brazilianpoliticalsciencereview

B OOK REVIEW

\title{
Critical Comparatives Perspectives in Water and Sanitation Systems*
}

\author{
Eduardo Marques \\ Universidade de São Paulo and Centro de Estudos da Metrópole, Brazil \\ (CASTRO, José Esteban and HELLER, Léo. Water and sanitation services: \\ public policy and management. London: Earthscan, 2009.)
}

The study of infrastructure services has long remained a field of technical studies
carried out by the engineering community or by economists and finance experts, with few exceptions. This absence of contributions from other areas has caused the presence and dissemination of what the authors of this book call "mainstream water and sanitation policies" general and standardised solutions for water and sanitation services (WSS) worldwide -, which have disregarded local processes and differences. This situation has had disastrous consequences in several countries and cities in the last few decades, and has been reinforced by policy solutions internationally disseminated by donor institutions and multilateral organisations.

The book edited by José Castro and Léo Heller offers a critical perspective of these policies. It aims to address the gap between the technical elements and social science analyses by critically discussing the recent provision of WSS all over the world. It is a product of successful research network "Governance, citizenship, water management and environmental health in developing countries" (Gobacit), which has promoted regular international seminars and is currently developing Waterlat (Research Network on Governance and Citizenship in Water Management and Environmental Health), with a focus on Latin America. This network's existence gives it stronger cohesion than what is usually found in edited volumes.

Although not all the chapters support the same position, the book clearly takes sides in the debates on the matter, supporting the claim that WSS should be considered social citizenship rights, understood within the logic of health promotion. They should therefore be organised institutionally so as to reach universality and equity. Based on this normative claim, several chapters develop the idea that WSS cannot be produced on the basis of market principles. Services based on the willingness to pay or on the principles of full cost recovery, promoted by international donors in recent years, are possibly incompatible with universality not only in countries of the so-called Global South, but also among poor social groups and ethnic minorities of the economically developed world.

Contrary to general formulas, the book states the importance in WSS provision of considering the specific conditions of countries, regions and cities, in terms of their physical, socio-economic, spatial, political and cultural dimensions. Therefore, diversity in institutional arrangements is considered a key element for the universal expansion of good quality and 
affordable services in different regions of the world.

Some of the book's contributors, however, hold diverging positions and defend the relevance and primacy of market mechanisms in developing WSS. Others emphasise the relevance of community organisation and mixed systems with participation by multiple agents in service provision. As a whole, the book creates a solid but nuanced critical account of mainstream WSS, while also presenting a broad and informative picture of how services are organised in different parts of the world.

The book includes an introduction and 21 chapters organised in two large parts, focusing on conceptual elements and country experiences, respectively. As in most edited volumes, the quality and style of the contributions vary, but the large majority of chapters are highly interesting and informative.

In the introduction, as well as presenting the book's chapters and structure, the organisers also outline its main ideas and the importance of studying WSS within a public policy approach based on the recognition of social rights.

This emphasis is repeated in the next chapters. The first chapter, by José Castro, defends the importance of considering the so-called systemic conditions - the social, political, economic and spatial characteristics of each case - when promoting WSS. From the consideration of these elements, the author criticises mainstream policies based on standardised proposals. In the following chapter, Erik Swyngedouw discusses the main contradictions present in treating WSS as commodities produced by a market rationale. The author deconstructs the premise of full cost recovery, stating that the real question is who should pay the costs to make the systems sustainable. In chapter 3, André Mulas introduces a conceptual framework for considering WSS as public policy, debating arguments from the literature, especially those regarding the financial arrangements associated with service provision.

In Chapter 4, Okke Braadbart develops an interesting historical account of the expansion of piped water and sewage in Europe and the US since the 19th century. The chapter shows that differently from what the literature states, health concerns were not at the origin of the first services, although they were responsible for the dissemination of these systems at a later date. The weakest part of this chapter concerns the movement of these systems to the Global South, as, in my opinion, the author homogenises a broad range of different situations. The cases of Rio de Janeiro and São Paulo, for example, were more similar to what the author describes in Europe than to his account of what took place in the Global South.

The following chapters present different models and principles for service provision. In Chapter 5, Osmo Sepala and Tapio Katko discuss the several European models for producing WSS. However, instead of presenting the European cases and constructing a typology, the chapter theoretically discusses the institutional and management elements involved in services provision. The subsequent contribution, by David Hall and Emanuel Lobina, is on the financial arrangements of WWS and builds a critique of what the authors call donor policy obsessions - cost recovery and private sector provision. The article states the importance of public taxation for financing services in a very compelling way. In Chapter 7, Léo Heller elaborates on the connections between WSS and health, defending the importance of an intersector approach for both service provision and research.

Chapter 8, by Michael Rouse, is probably the most divergent contribution from the book in terms of the policy solutions it advocates. It is the only contribution devoted to publicising and defending service provision by the market-centred paradigm. The author presents the argument and discusses well-known private failures in the US, Bolivia and China, as well as 
private provision successes in the UK, Chile and China.

In Chapter 9, Jarmo Hukka and Tapio Katko discuss the various arrangements present in the Finnish experience, deriving lessons about the necessity of flexible forms of service provision. The same nuanced position is found in Chapter 10, by Gordon McGranahan and Martin Mulenga, which focuses on community participation. This chapter presents a short, interesting account of community participation in WSS. Their argument is not that communities could replace market solutions or State provision, but that community organisation may enhance WSS production and delivery.

The second part of the book is devoted to current regional and country cases. Chapters 11 to 14 present European cases from France, Spain, Nordic countries and Europe as a whole, respectively. Christelle Pezon discusses the role of decentralisation and delegation of services to private providers in France. The first element is actually a historical legacy of the great territorial fragmentation of a large number of communes, although this has decreased since the 2000s. The second important characteristic of WSS in France involves a specific form of contracting out of services with public financing and a large degree of public control over the services. In chapter 12, David Sauri and colleagues discuss the Spanish situation. Service provision in Spain remains under the control of local government, although, similarly to France, private companies are increasingly becoming concessionaries. In recent years, full cost recovery policies have produced substantial increases in the cost of services, leading to several conflicts and struggles. The Nordic experiences are presented by Pekka Pietila and colleagues in the following chapter. Services in Denmark, Finland, Sweden, Iceland and Norway are highly decentralised and local government plays the most important role. Recent changes have reinforced the role of local administration. Although private companies carry out a substantial part of the operational activities, including provision of services and equipment, they do not manage the services, which are organised around principles of equity and universality. In Chapter 14, Bernard Barraqué uses historical evidences from several countries to summarise the provision of WSS in Europe. The chapter dialogues with and complements Chapter 4, giving a broad and informative overview of WSS in the continent. The author sustains that the design of solutions for WSS production and delivery should consider the differences in social structure and social solidarity present in each case, leading to a strong rejection of general models or solutions.

Chapters 15 and 16 discuss WWS provision in Canada and the US. Mark Rosenberg (Canada) and Venkatesh Uddameri and Vijay Singh (US) both suggest relatively similar situations - very high coverage levels, but inequality of access due to an ageing infrastructure and institutional disorganisation, which mainly affect the poor, immigrant groups and indigenous populations.

In Chapter 17, David Nilson and Arne Kaijser discuss the situation in African countries, mainly Uganda and Kenya. The article starts by mentioning the WSS inherited from the Colonial period, which concentrated on large and expensive systems. This paradigm systematically excluded the poor, creating an illegal private market of low-quality water delivery. Recent reforms have not changed this situation, since they were based on the principle of full cost recovery, excluding the poor from the services yet again. The authors discuss alternatives for service provision that could contribute by combining large systems with local distribution schemes.

In Chapter 18, Roldan Muradian and colleagues draw lessons from several local initiatives developed in Bangladesh and Nepal. Looking at the interface between public policy and community participation, the authors state the importance of actively including communities in WSS, especially in poor urban areas. This could lead to cost-sharing schemes, especially 
if service production and delivery is tailored to match local situations and actors. Focusing on Asia, Jiane Zuo and Lili Gan deal with WWS in China. In this case, the central government continues to play the main role in what is known as government-led management structures, which have produced increasing rates of service coverage, but also large inequalities, especially between urban and rural areas. In recent years, private firms have increasingly been participating in service design and construction, but not in management.

The last two chapters focus on Latin America. Léo Heller discusses the Brazilian case in Chapter 20. The author presents the historical legacy of WWS in Brazil inherited from the military period, as well as the most recent transformations introduced in the 2000s. Service continues to be provided by local government. Although municipalities have legal responsibilities, services are conceded to state level public companies in most cases. The federal government recently returned to the sector, but mainly with a financial and regulatory role. The author sustains that the recently introduced changes point in the direction of a more comprehensive and universal approach, but the production of concrete effects still depends on policy delivery. The final chapter, by María Armentia and Blanca Cisneros, discusses the Mexican case, marked by low coverage rates and intense inequalities. The federal government has been historically responsible for WSS provision, with limited participation by civil society and local government. The private sector has increasing participation in the services, in part due to a central government decentralisation policy, but is mainly involved in specific tasks rather than service provision or operation, which continue to be public and marked by clientelism. 